\title{
Type A behavior and temporal judgment
}

\author{
DONALD J. WARNER and RICHARD A. BLOCK \\ Montana State University, Bozeman, Montana
}

\begin{abstract}
Type A behavior is related to the development of coronary heart disease. Type A college students were compared with Type Bs on several time-related measures. The findings differ from what is expected on the basis of previous research and theories. Type As show greater variability and absolute error than do Type Bs in the production of a 60 - or 300 -sec duration, as well as marginally greater productions. Type As did not arrive earlier for the experiment and were not wearing a watch more frequently than were Type Bs. The results reveal difficulties in judging duration, which may help in understanding the Type A behavior pattern.
\end{abstract}

Type A individuals display a number of characteristics that are related to the development of coronary heart disease (Friedman \& Rosenman, 1974). Among the characteristics are feelings of time urgency and a chronic tendency to pursue many goals in a relatively short period of time. Individuals who do not show this very intense behavior pattern, who are referred to as Type Bs, are at a lower risk with regard to the development of coronary heart disease.

There is currently no unifying theory that accounts for all of the ways in which Type A characteristics are expressed (see Matthews, 1982). One possibility is that Type A behavior reflects a strategy for maintaining control over the person's environment that requires an accelerated pace of activities (Glass, Snyder, \& Hollis, 1974). A common idea is that the temporal experience of Type As is different from that of Type Bs. However, the exact nature of the difference remains obscure. Burnam, Pennebaker, and Glass (1975) found that Type As' mean production of a $60-\mathrm{sec}$ duration was shorter than that of Type Bs. They proposed that "time passes more slowly for the impatient. As than for the less impatient Bs" (p. 78). In other words, the experience of duration is assumed to be lengthened in Type As. Yarnold and Grimm (1982) obtained similar data, and they concluded that "Type A subjects perceived time as passing ... more quickly than Type B subjects" (p. 175). Matthews (1982) concluded that "persons who score high on the Jenkins Activity Survey [i.e., Type As] sense time passing rapidly" (p. 304). These and other seemingly discrepant conclusions may be a result of the use of misleading or inconsistent terminology to describe effects on duration experience (see Bindra \& Waksberg, 1956). It is also possible that methodological inadequacies and differences have pro-

This research was supported by National Science Foundation Grant ISP-8011449. We thank Susan Beattie for assistance in conducting the experiment. Thanks are also due Barbara QuigleyFernandez and George Rice for helpful comments. Requests for reprints should be sent to Richard A. Block, Department of Psychology, Montana State University, Bozeman, MT 59717-0001. cured both the equivocal findings and the replication failures that permeate the literature on duration judgment in Type A and Type B individuals. Some studies have used either an inadequate number of subjects or an inadequate methodology.

Another hypothesis is that there is no substantial lengthening or shortening of duration experience in Type As relative to that in Type Bs. Instead, Type A behavior may be partly a result of a relative inability to discriminate and to judge the passing of time. This kind of inability would tend to introduce randomness into Type As' duration judgments, randomness that would increase both the amount of variability among their judgments and the amount of absolute error of their judgments. The present study is designed to explore these possibilities.

The short form of Bortner's (1969; see also Bortner \& Rosenman, 1967) rating scale was used to classify each potential participant as either Type A or Type B. The Bortner scale was chosen for its brevity, ease of administration, and high predictive validity. It predicts Type A behavior with an accuracy similar to other surveys and inventories, such as the Jenkins Activity Survey, all of which are somewhat inferior to the lengthy standard interview originally used in the Western Collaborative Group Study (Rosenman, Friedman, Strauss, Wurm, Kositchok, Haan, \& Werthessen, 1964; see Matthews, 1982, for a review). In particular, Siegel and Leitch (1981) found that American adolescents classified by the Bortner scale differed on independent indexes of competitive achievement-striving and activity components of Type A behavior, although not on the hostility-aggressiveness component. Heller (1979) reported a relationship between Type A behavior assessed by the Bortner scale and the incidence of coronary heart disease in a sample of British men.

The method of production was used to assess duration experience. This method was chosen primarily for two reasons. First, it seems to be an ecologically valid index of the time urgency and impatience that is assumed to underlie Type A behavior, and it has been used in several studies of Type As (e.g., Burnam et al., 1975). 
Second, the method of production is apparently more sensitive to personality effects than are other methods, such as verbal estimation and reproduction (W. B. Davidson \& House, 1982). Subjects were asked to produce a relatively short $(60-\mathrm{sec})$ or a relatively long $(300-\mathrm{sec})$ time period. Previous findings reveal that the amount of error in duration judgment increases in proportion to the length of the time period. It is possible that there is an interaction between duration length and behavior type, such that Type As show increasingly greater error than do Type Bs in judgments of longer durations.

Two time-related behavioral measures, which are hypothesized to show a difference between Type As and Type Bs, were also taken. The extent to which a person's arrival time for the experiment differed from his or her scheduled time was calculated in order to assess further the assumed time urgency of Type As. Gastorf (1980) reported that Type As arrived relatively earlier than Type Bs for an experiment, but Lee and Innis (1983) failed to replicate this finding. In addition, we also recorded whether or not each subject was wearing or carrying a watch.

Finally, the present study includes an equal number of male and female Type A and Type B subjects. Only a few previous studies of Type A temporal experience and behavior have included women as participants, presumably because most medical research on coronary heart disease has focused on men. Research on duration experience has typically shown either small or ambiguous sex differences.

To summarize, the present study was concerned with identifying the nature of possible differences between Type As and Type Bs in temporal experience and behavior. If Type As are less able to discriminate the passing of time, they might show greater variability and absolute error in temporal production than Type Bs. Behavioral measures relating to punctuality and timekeeping might also reflect such a basic difference between Type As and Type Bs.

\section{METHOD}

\section{Subjects and Design}

A total of 584 students in three introductory psychology classes voluntarily completed the short form of Bortner's (1969) scale. Individuals who scored in the middle third of the distribution were subsequently excluded. Thus, all students classified as Type As scored at least 104.0, and all students classified as Type Bs scored at most 88.0 on the Bortner scale. This procedure produced a pool of 74 Type A males, 116 Type A females, 98 Type B males, and 98 Type B females.

A $2 \times 2 \times 2$ (behavior type $\times$ sex $\times$ duration length) factorial design was used. A total of 112 subjects, 28 of each combination of sex and behavior type, was selected randomly from the pool; then half of the subjects of each type were assigned randomly to each duration length. The mean Bortner score for Type A male participants was $113.6(S D=10.4)$, and the mean for Type $A$ females was $114.4(\mathrm{SD}=9.3)$; the two means are not significantly different $[t(54)=.03]$. The mean score for Type B male participants was $78.2(\mathrm{SD}=8.6)$, and that for Type $B$ females was $78.1(\mathrm{SD}=6.7)$; the two means are not significantly different $[t(54)=.03]$. The median age of all participants was 20.6 years.

\section{Apparatus and Procedure}

Several weeks after the Bortner scale was administered, the subjects were telephoned and were asked to participate in a psychological experiment. Each was encouraged to arrive promptly for the experiment at a specific time. When a subject arrived, he or she was seated in a waiting room and asked to remove any watch. The experimenter, who was blind to the personality type of the subject, recorded the arrival-time and watch-wearing data. Each subject was then led to and seated in a small $(3.2 \mathrm{x}$ $1.8 \times 2.9 \mathrm{~m}$ ) room, which contained only a desk-chair with a Lucite control box mounted on the desk surface. The control box had an on/off switch and a pilot lamp. Half of the subjects were told to turn on the light for a $1-\mathrm{min}$ time period, and the other half for a 5-min time period. All were instructed not to count or to use any similar method to estimate the duration. The switch controlled by the subject started and stopped a timer located in an adjacent room. Because the setting was an environment of minimal external stimulation, each participant had to rely on internal cues to judge the duration.

\section{RESULTS}

\section{Duration Judgment}

The duration-judgment data were subjected to several analyses of variance. In none of them was there a significant main effect or interaction involving sex [all $\mathrm{Fs}(1,104)<1.13]$, so all duration-judgment data reported here are collapsed across sex.

An important finding is that the mean production by Type As is somewhat longer than that by Type Bs for both the short duration $(63.3 \mathrm{sec}$ vs. $56.7 \mathrm{sec})$ and the long duration ( $339.8 \mathrm{sec}$ vs. $290.1 \mathrm{sec})$. The main effect of behavior type is marginally significant $[F(1,104)=$ $3.20, p<.10]$, and the interaction of behavior type and duration length is not significant $[F(1,104)=1.87]$. Not surprisingly, the main effect of duration length is significant $\cdot[F(1,104)=262, p<.001]$.

The absolute deviation of each production from the corresponding cell mean, which is an index of the variability of duration judgments within each cell, was analyzed by using Levene's (1960) test for heterogeneity of variance. The analysis reveals a major finding of the present study: The mean absolute deviation of the productions by Type As is greater than that by Type Bs for both the short duration $(19.8 \mathrm{sec}$ vs. $10.6 \mathrm{sec})$ and the long duration $(106.2 \mathrm{sec}$ vs. $72.2 \mathrm{sec})$. In other words, productions by Type As are more variable than those by Type Bs $[F(1,104)=5.60, p<.05]$. The interaction of behavior type and duration length is not significant $[F(1,104)=1.85]$. As expected, the main effect of duration length is significant $[F(1,104)=65.8$, $\mathrm{p}<.001]$.

The absolute error of each production-that is, the absolute deviation of each production from the objective standard (either 60 or $300 \mathrm{sec}$ )-was also analyzed. The analysis reveals greater mean production error by Type As than by Type Bs for both the short duration $(20.6 \mathrm{sec}$ vs. $12.2 \mathrm{sec})$ and the long duration $(106.3 \mathrm{sec}$ vs. $72.2 \mathrm{sec}$ ). In other words, productions by Type As are less accurate than those by Type Bs $[F(1,104)=4.27$, $\mathrm{p}<.05]$. The interaction of behavior type and duration is not significant $[F(1,104)=1.63]$. However, the effect 
of duration length is significant $[F(1,104)=52.4$, $\mathrm{p}<.001]$.

\section{Arrival Time}

Arrival-time behavior was measured as the number of seconds that a subject arrived early or late. Overall, the subjects tended to arrive early. The mean arrival time of females is earlier than that of males for both Type As (3.01 min early vs. $0.84 \mathrm{~min}$ early) and Type Bs ( $4.60 \mathrm{~min}$ early vs. $1.36 \mathrm{~min}$ early). The main effect of sex is significant $[F(1,108)=5.00, p<.05]$. However, neither the main effect nor the interaction involving behavior type is significant [both $\left.\mathrm{F}_{\mathbf{S}}(1,108)<1\right]$.

The mean absolute deviation (AD) of each arrival time from the corresponding cell mean was also analyzed by using Levene's (1960) procedure. Type B males showed considerably less arrival-time variability (mean $\mathrm{AD}=2.81 \mathrm{~min}$ ) than did Type $\mathrm{A}$ males (mean $\mathrm{AD}=$ $6.24 \mathrm{~min})[\mathrm{t}(54)=4.78, \mathrm{p}<.001]$ and Type $\mathrm{B}$ females (mean $\mathrm{AD}=6.15 \mathrm{~min})[\mathrm{t}(54)=2.86, \mathrm{p}<.01]$, and marginally less than did Type $\mathrm{A}$ females (mean $\mathrm{AD}=$ $4.58 \mathrm{~min})[\mathrm{t}(54)=1.78, \mathrm{p}<.10]$. There is no main effect of either behavior type or sex [both $\mathrm{Fs}_{s}(1,108)<$ $1.10]$; however, the interaction of the two variables is reliable $[\mathrm{F}(1,108)=7.91, \mathrm{p}<.01]$.

\section{Watch Wearing}

Watch-wearing behavior was analyzed by a $2 \times 2$ analysis of variance. (The use of $\chi^{2}$ tests yields identical conclusions.) Proportions of .46 Type A males and .68 Type B males wore a watch to the experiment, whereas only .36 Type A females and .29 Type B females wore one. The main effect of sex is significant $[F(1,108)=7.50, p<.01]$. However, neither the main effect of behavior type $[\mathrm{F}(1,108)<1]$ nor the interaction of the two variables $[F(1,108)=2.45]$ is significant.

\section{DISCUSSION}

A major finding of the present study is that temporal productions by Type As show greater variability and absolute error than do those by Type Bs. Both may reflect a greater level of randomness in judgments by Type As than in those by Type Bs. The randomness may be attributable either to a greater variability of physiological or cognitive processes that underlie duration judgment or to a lesser sensitivity to the processes.

Matthews's (1982) conclusion that Type As tend to perceive time as passing more rapidly than do Type Bs is clearly not supported by the present evidence. In fact, under the present experimental conditions, Type As showed slightly greater productions than did Type Bs. This marginally significant effect is in the opposite direction from that obtained by Burnam et al. (1975) and Yarnold and Grimm (1982). It is possible that methodological differences between the present study and those of Burnam et al. and Yarnold and Grimm are responsible for the discrepant findings. Specifically, the present study classified subjects by using the Bortner scale, whereas the others used the Jenkins Activity Survey; and the duration here was "unfilled," whereas the other studies used a duration filled by reading.
Further investigation is clearly needed on the issue of duration experience of Type As relative to that of Type Bs.

Another interesting finding is that there is no effect of sex and no interaction of sex and personality type on any of the measures of duration judgment. Type A individuals, especially those who develop coronary heart disease, are usually characterized as hard-driving, time-conscious males in positions of authority or other stressful occupations. It may be that the greater variability in duration experience of Type As, as compared with that of Type Bs, is not a factor in coronary heart disease. Alternatively, perhaps the underrepresentation of women among coronary patients is a result of the decreased opportunity of women to be placed in an appropriately pathogenic environment. A recent study comparing males and females who occupy comparable positions found similarities in the pathognomonic indicators of Type A behavior (M. J. Davidson, Cooper, \& Chamberlain, 1980).

Our behavioral measures of arrival time and watch wearing also yielded some unexpected findings. The results fail to replicate Gastorf's (1980) finding that Type As arrive earlier for an experiment than do Type Bs. In fact, our results are in the opposite direction, although not significantly. The results are more similar to those of Lee and Innis (1983), who recently reported a failure to replicate Gastorf's findings. Our most striking effects involve sex: Females tend to arrive relatively earlier than males, and fewer of them wear watches. Neither Gastorf nor Lee and Innis found an effect of sex on arrival time, and neither obtained watch-wearing data. The differential frequency of watch wearing between males and females may partially explain the present finding that males tended to arrive closer to their scheduled time than did females. In addition, the greatest proportion of watches was worn by male Type Bs, who also showed the least variability in arrival time. It seems that whether or not a person wears a watch may affect his or her punctuality, or vice versa. These results are surprising, because if one assumes that Type As are more time conscious than Type Bs, Type As should tend to wear a watch more frequently than should Type Bs, rather than less frequently. The findings are also unexpected in the light of the present evidence that Type As show greater variability and greater absolute error in duration judgment. Wearing and using a watch should be expected to compensate for the relatively unreliable temporal judgments of Type As, but apparently this strategy is not used, at least not by our subjects.

In conclusion, the results of the present study suggest that difficulties in judging duration may be related to the Type $A$ behavior pattern. Our society requires and reinforces the ability to perform under conditions of temporal constraint. This selection may provide part of the environmental context in which the Type A pattern develops. Coupled with temporal constraint, increased variability of duration experience may produce anxiety and thereby activate the sympathetic nervous system, producing a chronic cardiovascular arousal pattern. Furthermore, in order for individuals who have difficulty in judging the passing of time to achieve a consistent level of success in their lives, it may become important for them to develop an extreme time consciousness. Preoccupation with time may underlie the common assumption that duration experience is lengthened in Type As relative to Type Bs, because it is well known that attention to time lengthens prospective duration experience (see Block, 1979, for a review). Perhaps the expected effect of behavior type on duration judgment was not found in the present study because all subjects were required to attend to time in order to perform the production task. Thus, it is possible that Type A individuals live at an accelerated experiential pace. It is an open question as to whether or not Type $A$ individuals could be taught to discriminate more reliably the passing of time, and whether or not such training might lower the incidence of coronary heart disease. At present, differences in temporal ex- 
perience characteristic of Type As have not been shown to be pathogenic, and there are no studies in which a modification of temporal experience has been shown to reduce the incidence of coronary heart disease.

\section{REFERENCES}

Bindra, D., \& WAKsBerg, H. (1956). Methods and terminology in studies of time estimation. Psychological Bulletin, 53, 155-159.

BLock, R. A. (1979). Time and consciousness. In G. Underwood \& R. Stevens (Eds.), Aspects of consciouness: Vol. I. Psychological issues (pp. 179-217). London: Academic Press.

Bortiner, R. W. (1969). A short rating scale as a potential measure of pattern A behavior. Journal of Chronic Diseases, 22, 87-91.

Bortner, R. W., \& Rosenman, R. H. (1967). The measurement of pattern A behavior. Journal of Chronic Diseases, 20, 525-533.

Burnam, M. A., Pennebaker, J. W., \& Glass, D. C. (1975). Time consciousness, achievement striving, and the Type A coronary-prone behavior pattern. Journal of Abnormal Psychology, 84, 76-79.

Davidson, M. J., Cooper, C. L., \& Chamberlain, D. (1980). Type A coronary-prone behavior and stress in senior female managers and administrators. Journal of Occupational Medicine, 22, 801-805.

Davidson, W. B., \& House, W. J. (1982). Personality and the perception of time: A multimethod examination. Psychology: A Quarterly Journal of Human Behavior, 19, 7-11.

Friedman, M., \& Rosenman, R. (1974). Type $A$ behavior and your heart. New York: Knopf.
GAstorf, J. W. (1980). Time urgency of the Type A behavior pattern. Journal of Consulting and Clinical Psychology, 48, 299.

Glass, D. C., Snyder, M. L., \& Hollis, J. F. (1974). Time urgency and the Type A coronary-prone behavior pattern. Journal of Applied Social Psychology, 4, 125-140.

Heller, R. F. (1979). Type A behavior and coronary heart disease. British Medical Journal, 1979-2(Serial No. 6168), 368.

LEe, C., \& InNis, J. M. (1983). Type A behavior pattern, time urgency and arrival time: A replication. Perceptual and Motor Skills, 56, 177-178.

Levene, H. (1960). Robust tests for equality of variances. In I. Olkin (Ed.), Contrubutions to probability and statistics (pp. 278-292). Stanford, CA: Stanford University.

Matrhews, K. A. (1982). Psychological perspectives on the Type A behavior pattern. Psychological Bulletin, 91, 293-323.

Rosenman, R. H., Friedman, M., Strauss, R., Wurm, M., KositchoK, R., HahN, W., \& Werthessen, N. T. (1964). A predictive study of coronary heart disease: The Western Collaborative Group Study. Journal of the American Medical Association, 189, 15-22.

Siegel, J. M., \& Leitch, C. J. (1981). Assessment of the Type A behavior pattern in adolescents. Psychosomatic Medicine, 43, 45-56.

YARnOLD, P. R., \& Grimm, L. G. (1982). Time urgency among coronary-prone individuals. Journal of Abnormal Psychology, 91, 175-177.

(Manuscript received for publication January 12, 1984.) 